\title{
The Role of Vertical Segregation in Semitransparent Organic Photovoltaics
}

\author{
Alexander Kovalenko ${ }^{1,2}$, Antonio Guerrer $0^{1 *}$, and Germà Garcia-Belmonte ${ }^{1 *}$ \\ 1 Photovoltaic and Optoelectronic Devices Group, Departament de Física, \\ Universitat Jaume I, ES-12071 Castelló, Spain \\ 2 Brno University of Technology, Faculty of Chemistry, Materials Research Centre, \\ Purkyňova 118, 61200 Brno, Czech Republic
}

\section{Email: $\underline{\text { aguerrer@uji.es, }}$ garciag@uji.es, \\ Abstract}

In this work the efficiency of semitransparent Organic photovoltaic (OPV) devices for low intensity applications is investigated as a function of the processing conditions. It is observed that a thermal treatment of the organic layer induces fullerene migration towards the active layer/air interface. This physical process gives rise to different vertical segregation profile of donor and acceptor molecules. Once the back contact is deposited the amount of fullerene covering the surface will determine the contact selectivity and leakage current of the device. Control of this leakage current may not be essential for devices fabricated for high illumination conditions applications. However, devices to be used under low illumination conditions may be highly influenced by the presence of this parasitic dark current which flows in the opposite direction to photogenerated current. At the proximity of the contacts the vertical segregation profile is inferred from optical and electrical measurements. In particular, External Quantum Efficiency (EQE) measurements carried out from a relatively opaque back contact provide local information on the materials spatially close to the light source. Alternatively, Capacitance-Voltage measurements enable calculation of the percentage of fullerene molecules covering the cathode contact. Overall, a versatile method that can be used in regular and inverted configuration is presented that explain the different behavior observed for devices to be used under low illumination conditions.

Keywords: Organic photovoltaics, low illumination conditions, contact selectivity, Capacitance-Voltage, impedance spectroscopy. 


\section{Introduction}

Organic Photovoltaics (OPV) have been studied for nearly 30 years and the technology is now on the verge of commercialization. With record power conversion efficiencies slightly exceeding $10 \%$ OPV still lag behind other technologies such as

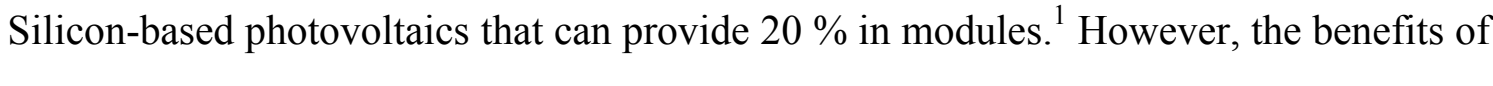
OPV rely on the possibility to produce flexible and low weight products with a high degree of design freedom with very rapid payback times ${ }^{2}$ In addition, it has been claimed that OPV can overperform silicon technology under low light conditions ${ }^{3}$ These advantages and the ease of handling in subsequent product-integration processes will enable its implementation into new consumer and portable electronics such as building-integrated photovoltaic (BIPV) products. "Futuristic" products with valueadded applications may be envisaged such as the use of semitransparent windows BIPV that permit both natural or color designed room illumination with production of solar electricity. Such a semitransparent device could additionally function during the night as a room light scavenger working under low illumination conditions to recover part of the "wasted" illumination energy.

The search for new semitransparent electrodes have made available a range of materials such as thin Ag electrodes, Ag nanowire $\$$. free-standing carbon nanotub $\rrbracket^{5}$ or highly conductive PEDOT:PS\$. Using all the knowledge learnt from OPVs during the last decade semitransparent devices with conversion efficiencies (PCE) as high as of 5.4 $\%$ in single laye 7 or $7 \%$ in tandem configuration ${ }^{8}$ have been obtained with average transmission of $30 \%$. Alternatively, PCE of $6.4 \%$ have been achieved with a maximum transmission of $51 \%$ at $550 \mathrm{~nm}$ in the tandem configuration ${ }^{8}$ Unfortunately, any information related to the physical requirements or working principles for devices to be used under low light intensities is rather scarce.

It is well known that morphology of the donor:acceptor blend of the organic layer is a critical aspect towards the final device efficiency ${ }^{9-10}$ For this reason several processing conditions have been developed which enable adequate morphology in the bulk of the organic blend. ${ }^{\top}$ Additionally, selectivity of the contacts play a very important role as an adequate vertical phase segregation of the donor and acceptor molecules is required where the fullerene molecules are in close contact with the selective layer to electrons 
and the polymer with the electrode selective to holes ${ }^{12-13}$ For example, it is known that a thermal or solvent annealing is an essential procedure for standard P3HT:PCBM bulk heterojunction (BHJ) solar cells to improve solar cells efficiency by creating appropriate morphology and vertical phase segregation ${ }^{14}$ Importantly, this vertical segregation depends on the substrate where the organic layer is deposited and different device architectures may be designed to enable contacts rich on either polymer or fullerene

A range of different techniques have been developed to study segregation of donor and acceptor molecules within the active layer. ${ }^{15}$ Amongst the different types some provide 3D structural information of the bulk of the active layer and include grazing incidence X-ray diffraction (GIXRD), variable-angle spectroscopic ellipsometry (VASE), transmission electron microscopy (TEM) or secondary ion mass spectrometry (SIMS) ${ }^{16}$ Alternatively, other techniques look into the active layer/air interface and include techniques such as atomic force microscopy (AFM), Scanning electron microscopy (SEM) or Capacitance-Voltage (C-V). The abovementioned techniques are complementary and each presents their own limitations that make them inaccessible to many research labs. For example, most of them require sophisticated and expensive equipment (GIXRD or TEM), some are destructive (SIMS, GIXRD or TEM) and most do not allow the measurement on working devices being the exception C-V and VASE (if very thin contact layers are used), as a drawback they are both non-direct techniques that requires mathematical estimations. Of particular interest for the purpose of the present work is the use of a purely electrical technique such as $\mathrm{C}-\mathrm{V}$ able to provide information on the donor/acceptor ratio at the cathode contact in completed devices ${ }^{13}$

This work is focused on providing clear understanding about the role of contact selectivity on semitransparent devices operating under low illumination conditions. For the different configurations studied a thermal treatment induces the migration of fullerene molecules towards the active layer/air interface which will ultimately determine the contact selectivity. Shunt resistance under varied illumination (photoshunt) is observed to be a determining parameter especially under low irradiation. Indeed, the selection of regular or inverted architecture as well as the processing conditions is a critical feature to take into account for devices to be used under low illumination conditions. 


\section{Experimental}

\section{Materials}

P3HT (Luminescence Technology Corp.), PCBM ( $\mathrm{PC}_{60} \mathrm{BM}$, Solenne, 99 \%), odichlorobenzene (Aldrich, 99.9 \%), PEDOT:PSS (CLEVIOS P Al 4083), ZnO (Gene's Ink), $\mathrm{Ca}$ (Aldrich, $99.995 \%$ ), $\mathrm{MoO}_{3}$ (Aldrich, $99.98 \%$ ) and $\mathrm{Ag}$ (Aldrich, $99.99 \%$ ) were used as received without further purification. Pre-patterned ITO (Xin Yan, XY10S) was cleaned with detergent and sonication followed by several rinsing steps with water, ethanol and isopropanol. Organic matter was removed by introducing the devices into UV-ozone chamber for $15 \mathrm{~min}$. The active layer films were prepared from the P3HT:PCBM solution (1:0.8 by weight) in o-dichlorobenzene $\left(17 \mathrm{mg} \mathrm{mL}^{-1}\right)$ and were stirred at $80^{\circ} \mathrm{C}$ for 12 hours until complete dissolution. The concentration in odichlorobenzene solvent of the pure P3HT and PCBM solutions were $17 \mathrm{mg} \mathrm{mL}^{-1}$ and $13.6 \mathrm{mg} \mathrm{mL}^{-1}$, respectively. All manipulations were carried out in a glove box under a nitrogen atmosphere unless otherwise stated.

\section{Device fabrication}

For the regular device architecture glass substrates with patterned ITO were covered by PEDOT:PSS by spin coating at $5500 \mathrm{rpm}$ for 60 seconds. Films were dried by annealing for 10 minutes at $120^{\circ} \mathrm{C}$ in air followed by a further thermal treatment in the glovebox for another 10 minutes at $110^{\circ} \mathrm{C}$ to remove residual moisture. In case of inverted architecture, $\mathrm{ZnO}$ nanoparticles dispersed in isopropanol were deposited by the spincoating procedure of at $1000 \mathrm{rpm}$ for 40 seconds onto the glass/ITO substrates to form $30 \mathrm{~nm}$ layer and then annealed for 30 seconds at $75^{\circ} \mathrm{C}$. Polymer-fullerene heterojunction layer was created by spin coating of $55 \mu$ of prepared P3HT:PCBM solution at $1200 \mathrm{rpm}$ for 15 seconds, the wet film was solvent annealed in a petri dish for 60 minutes (Solvent annealed). Half of the considered devices were further thermally treated at $130^{\circ} \mathrm{C}$ for 10 minutes to obtain the second set of processing conditions (Solvent + Thermal annealed). Top electrodes were deposited by sequential evaporation of $\mathrm{Ca}(7)$ and $\mathrm{Ag}(30 \mathrm{~nm})$. Alternatively, for inverted devices $\mathrm{MoO}_{3}(5 \mathrm{~nm}) / \mathrm{Ag}(25 \mathrm{~nm})$ was evaporated. In both type of device configurations semitransparent back electrode were obtained. A total of 10 devices were measured using each of the conditions mentioned above. 


\section{Characterization techniques}

Film thickness was determined by a VEECO DEKTACK 6M Stylus Profiler. The current density-voltage measurements were carried out under illumination using an Abet Sun 2000 solar simulator with an air mass (AM) 1.5G filter. The simulated light intensity was adjusted to $1000 \mathrm{~W} \mathrm{~m}^{-2}$ by using a NREL-calibrated Si solar cell. Low illumination conditions were created by using calibrated perforated sheets commercially available (ABET) which do not modify the spectrum of the light whilst maintaining the light homogeneity. External Quantum Efficiency (EQE) measurements were performed using a $150 \mathrm{~W}$ Xe lamp coupled with a monochromator controlled by a computer. The light intensity was measured using an optical power meter 70310 from Oriel Instruments where a Si photodiode was used to calibrate the system. Capacitance-Voltage data were measured using a Autolab PGSTAT-30 equipped with a frequency analyzer module, small voltage perturbation $(20 \mathrm{mV} \mathrm{rms})$ at $1000 \mathrm{~Hz}$ was applied in dark conditions.

\section{Results and discussion}

A set of semitransparent devices were prepared in the configuration ITO/PEDOT:PSS/P3HT:PCBM/Ca/Ag as displayed in Figure 1. Semitransparency of the back electrode provided maximum transmittance of $26 \%$ at $440 \mathrm{~nm}$ and average transparency in the visible region $(390-700 \mathrm{~nm})$ of $15 \%$ that allows illumination from both sides (see in Supporting Information Figure SI1). Two different approaches to provide adequate morphology were followed, in the first the organic layer was spin coated and when still wet was introduced into a petri dish to slowly dry the organic layer during $1 \mathrm{~h}$. In a second method after solvent annealing devices were thermally treated at $120{ }^{\circ} \mathrm{C}$ for 10 minutes. The different set of conditions will be denoted in the manuscript as solvent annealing and solvent + thermal annealing, respectively. The bulk morphology of the films using the different conditions did not differ significantly in terms of domain size/shape as can be observed in the dark field TEM images shown in the supporting information (Figure SI2). Devices were electrically and optically characterized by using different techniques. 

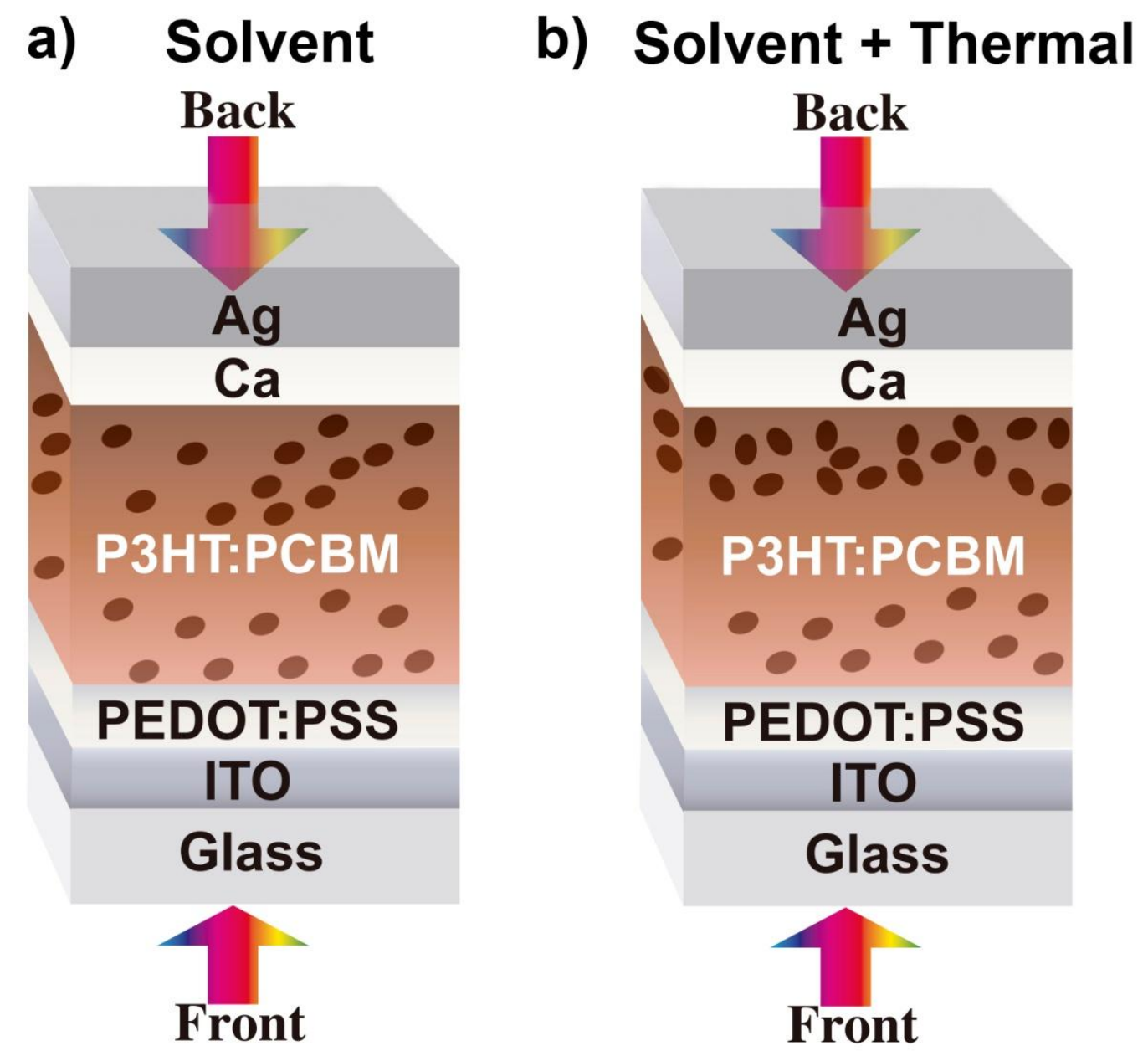

Figure 1: Scheme of the semitransparent device configuration indicating the different processing conditions used. Devices have been either illuminated from the ITO/PEDOT:PSS (Front) or from the semitransparent $\mathrm{Ca} / \mathrm{Ag}$ electrode (Back). Fullerenes migration induced by thermal treatment is schematically represented by showing a higher concentration of dots (fullerenes) close to the $\mathrm{Ca} / \mathrm{Ag}$ electrode.

Device performance parameters were analyzed under different light intensity conditions using a solar simulator. Here, the spectrum of $1.5 \mathrm{G}$ (AM) was not modified by using metal perforated sheets to reduce the power intensity whilst maintaining the light homogeneity. Efficiency of photovoltaic devices is calculated as a function of the light intensity of the illumination source as PCE $=\left(\mathrm{J}_{\mathrm{sc}} \times \mathrm{V}_{\mathrm{oc}} \times \mathrm{FF}\right) / \mathrm{I}_{0}$. Where $\mathrm{J}_{\mathrm{sc}}$ is the current at short circuit, $\mathrm{V}_{\mathrm{oc}}$ is the open circuit current, FF the Fill Factor and $\mathrm{I}_{0}$ the light intensity of the source. Both processing conditions provided similar PCE under one sun light intensity conditions as shown in Table 1 (front illuminated 2.6-2.7\%). Interestingly, when the light intensity is reduced only the device processed using both solvent and thermal annealing retains the efficiency under low light intensity conditions. 
On the other hand, the device solvent annealed dramatically reduces the PCE and at 330 $\mathrm{Wm}^{-2}$ the efficiency is already half of that observed at 1 sun (Figure 2). Interestingly, this drop in efficiency clearly correlates with a drop in the achievable photocurrent of the device. Here the $\mathrm{J}_{\mathrm{sc}}$ has been normalized to take into account the difference in light intensity. In order to provide understanding on these observation further electrical measurements were carried out.

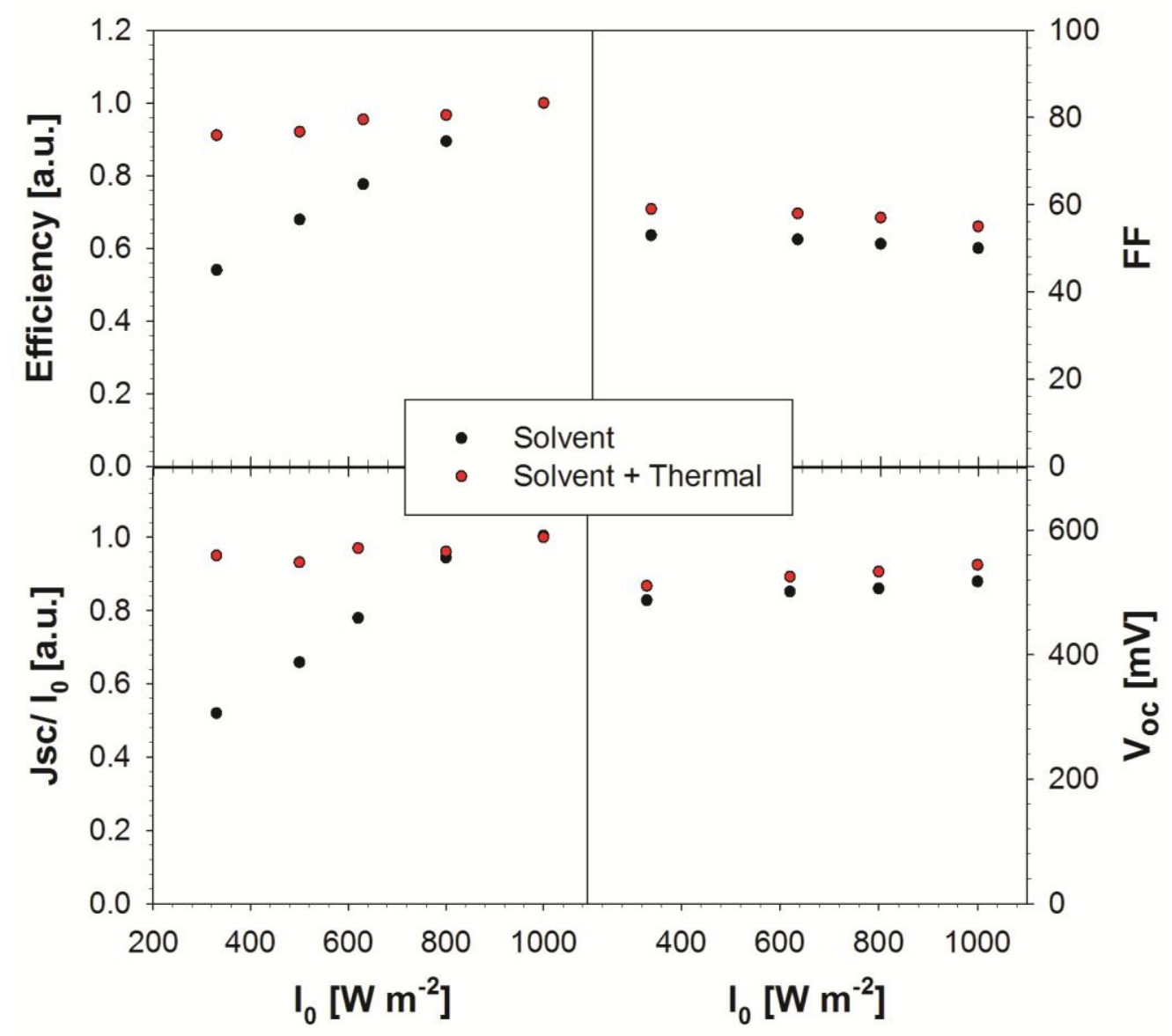

Figure 2: Performance parameters measured under different light intensity conditions. Whilst devices processed using solvent annealing conditions dramatically reduce they PCE mainly due to a decrease in photocurrent, devices which undertook a further thermal annealing treatment maintain the efficiency. Obtained $\mathrm{J}_{\mathrm{sc}}$ values in $\mathrm{mA} / \mathrm{cm}^{2}$ are indicated in the $\mathrm{Jsc} / \mathrm{I}_{0}$ graph for the devices solvent annealed.

Current density vs voltage curves of devices were measured from both semitransparent sides being front and back illumination as depicted in Figure 1, ITO/PEDOT:PSS (Front) and $\mathrm{Ca} / \mathrm{Ag}$ (Back). In both measurements devices processed 
with only solvent annealing provided slightly better performance as shown in Figure 3 in good agreement with previously reported data for P3HT:PCBM with similar levels of transparency ${ }^{14}$ Performance parameters are in the range of $2.7 \%$ illuminating from the front and drops to about $0.7 \%$ if illuminated from the $\mathrm{Ca} / \mathrm{Ag}$ side as a significant part of the light is absorbed/reflected by the metal layers. Interestingly, if we take into account the low transparency of the back contact efficiency when the device is illuminated from $\mathrm{Ca} / \mathrm{Ag}$ is remarkably high. Fill Factors are in the order of $60 \%$ and slightly increased when illuminated from the Back electrode. The obtained high efficiency when illuminated from $\mathrm{Ca} / \mathrm{Ag}$ electrode correlates with an improvement in the fill factor and an increase of the shunt resistance.

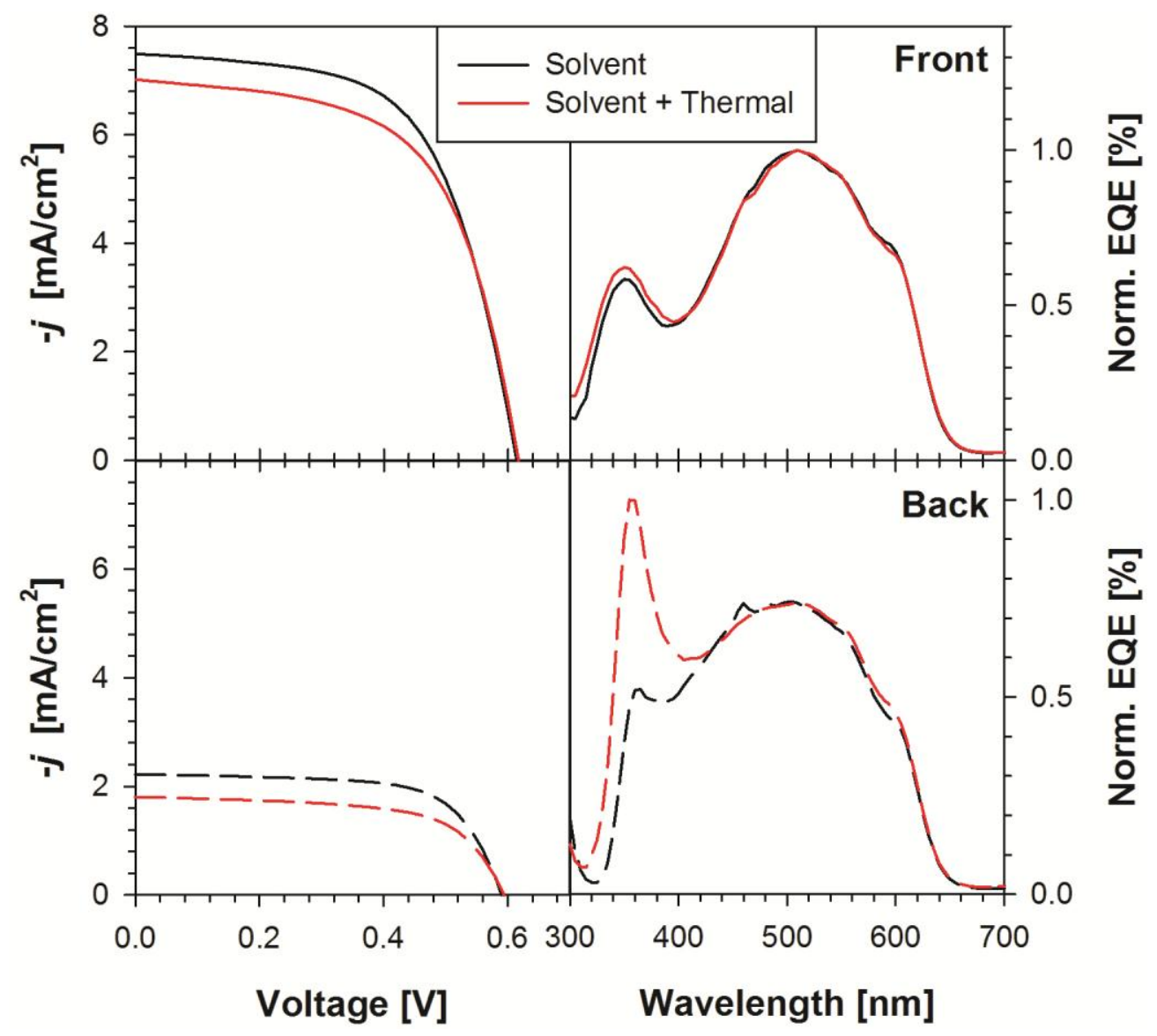

Figure 3: J-V curves of P3HT:PCBM devices processed by either solvent annealing or by having and additional thermal treatment. Normalized External quantum efficiency of measurements carried out illuminating from the Devices have been either illuminated from the ITO or from the semitransparent Silver electrode (Back).

External quantum efficiency (EQE) measurements are shown in Figure 3. When 
devices are illuminated from the front contact (ITO/PEDOT:PSS) no noticeable spectra differences are observed between the two processing conditions. Strikingly, when EQE are recorded by illumination from the back electrode the relative contribution to the photocurrent of PCBM $(<450 \mathrm{~nm})$ and P3HT $(\sim 400-650 \mathrm{~nm})$ is seriously affected by the processing conditions used in each device. Therefore EQE measurement illuminating from the back electrode (highly opaque) provides local information on the materials actually close to the semitransparent contact. It is important to note that EQE is in general a technique carried out under low illumination conditions and its use by illumination of the back contact further reduces the intensity of the light. Therefore, local concentration may be detected as a result of using both low light intensity and materials with high extinction coefficient in the organic layer. This correlation of EQE response and local information of the back contact will be further supported below for devices prepared with an inverted configuration. For the regular configuration the relative fullerene/polymer intensity ratio of $\mathrm{EQE}$ peaks increases for the device thermally annealed thus indicating that fullerene molecules contribute more to the photocurrent than in the case of solvent annealed devices. These results can be explained in terms of vertical segregation of the fullerene polymer across the active layer. This would be the result of PCBM molecules migrating towards the active layer/air interface by the use of the thermal treatment. Therefore, once the cathode contact is deposited fullerene molecules will be in contact with the $\mathrm{Ca} / \mathrm{Ag}$ improving the contact selectivity as it will be discussed below. ${ }^{2}$

We have previously described a method to calculate the proportion of fullerene molecules in close contact with the cathode which relies on a purely electrical technique such as Capacitance-Voltage ${ }^{13}$ In this methodology the flat-band potential $\left(\mathrm{V}_{\mathrm{FB}}\right)$ or potential required to provide a flat band profile is correlated with the band-bending of the organic layer at the vicinity of the cathode and generation of a dipole at the interface ${ }^{17}$ The magnitude of such a dipole depends on the amount of fullerene molecules in contact with the cathode being higher for a high proportion of fullerene molecules which in turns reduces the magnitude of the $\mathrm{V}_{\mathrm{FB}}$. This method has already been used for a range of materials such as $\mathrm{PTB} 7: \mathrm{PC}_{71} \mathrm{BM}{ }^{18}{ }^{19}$ In addition, fullerene content calculated with this method correlates with other advanced microscopy techniques such as the nanoscale mapping by electron energy-loss spectroscopy ${ }^{20}$ It is 
important to note that the final proportion of fullerene/polymer at the top of the active layer blend is highly dependent not only on the processing conditions of the active layer but also on the substrate on which the active layer is deposited ${ }^{12}$ Indeed, formation of a skin layer of polymer has also been observed in the literature ${ }^{21-23}$ Here we observe that $\mathrm{V}_{\mathrm{FB}}$ shifts significantly with the processing conditions from $0.47 \mathrm{~V}$ (solvent) to $0.35 \mathrm{~V}$ (solvent + thermal). Preparing devices with full coverage of either polymer or fullerene (see Supporting Information) we can correlate these $\mathrm{V}_{\mathrm{FB}}$ values with fullerene coverage of $97 \%$ and $68 \%$, respectively. Therefore, based on these results it can be clearly conclude that devices processed using solvent and thermal annealing show high coverage of fullerene molecules. Therefore high electron selectivity of the cathode contact is assured by the presence of fullerene molecules contacting the cathode.

The current measured under dark conditions that can be extracted from the diode curves at negative bias is known to be a measurement of the leakage current of the device (Figure 4a), results are summarized in Table 1. Values of the leakage current are proposed as a guide on the selectivity of the contacts encountered at high illumination conditions. High current at negative bias and low shunt resistance is then a clear sign of devices with contacts poorly selective. Figure $4 \mathrm{~b}$ shows how $\mathrm{R}_{\mathrm{sh}}$ increases with a reduction of the light intensity for both devices. However, the difference between values is small at 1 sun light intensity $\left(930 \Omega \mathrm{cm}^{2}\right)$ increasing at low illumination conditions $\left(2054 \Omega \mathrm{cm}^{2}\right.$ ). Similarly, when the device is illuminated from $\mathrm{Ca} / \mathrm{Ag}$ the light intensity is reduced and $\mathrm{R}_{\mathrm{sh}}$ increases to similar levels as those observed for illumination from the ITO side at low light intensity levels, see Table 1. This behavior relates to the occurrence of a light-dependent leakage current giving rise to a photoshun ${ }^{24}$ presumably related to the selectivity features of the cathode contact. Importantly, at low illumination conditions there is a clear competition between the dark and photogenerated currents as both flow in opposite direction as depicted in Figure 4c. Indeed, the dark current at negative bias (-1 V) for the device only solvent annealed $\left(0.57 \mathrm{~mA} \mathrm{~cm}^{-2}\right)$ represents already a $50 \%$ of the obtained $\mathrm{J}_{\mathrm{sc}}$ at $330 \mathrm{Wm}^{-2}(1.13 \mathrm{~mA} \mathrm{~cm}-$ ${ }^{2}$ ). For comparison purposes the $\mathrm{J}_{\mathrm{sc}}$ obtained at the different light intensity conditions for the solvent annealed devices are shown in Figure 2. In this case, the observed photocurrent decrease at low illumination conditions is clearly connected with the 
relative increase in leakage current and the low proportion of fullerene molecules covering the cathode contact. Importantly, no difference in the expected photocurrent is observed for a device that shows a highly selective cathode as that obtained from the solvent and thermal annealing. This correlation between fullerene coverage at the cathode, contact selectivity and leakage current suggests an interfacial origin for the photoshunt effect shown in Fig. 4b, although our measurements are not conclusive and do not allow discarding a bulk origin for the light-dependent leakage current. 

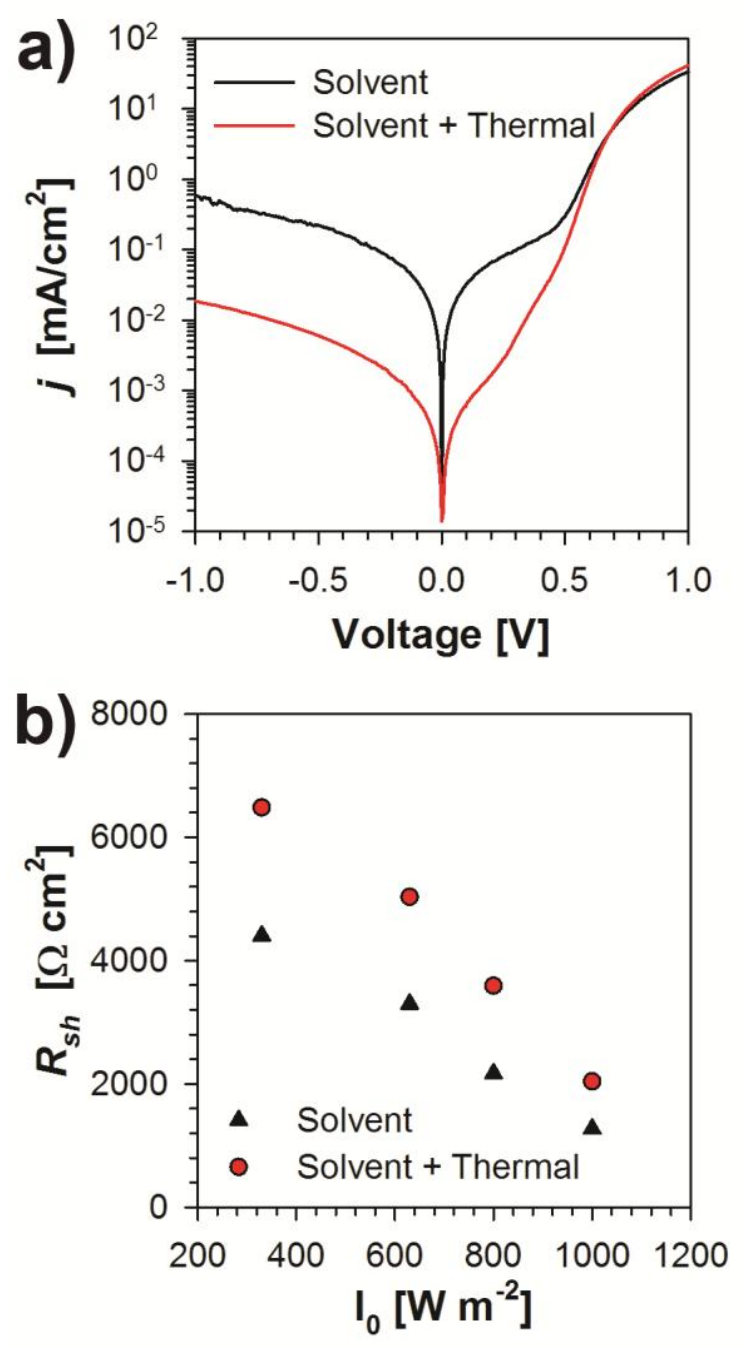

\section{C) Power generation quadrant}

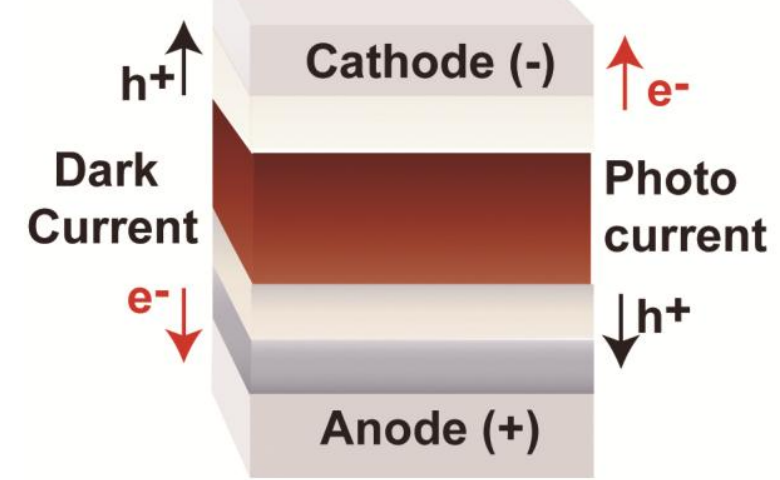

Figure 4. a) Diode curve measured under dark conditions for the two devices under study. b) Variation of shunt resistance as a function of the light intensity. c) Scheme of current flow for dark current and photocurrent in the power generation quadrant. 
Interestingly, in an inverted configuration (ITO/ZnO/P3HT:PCBM/ $\mathrm{MoO}_{3} / \mathrm{Ag}$ ) similar behaviour to that observed in the regular configuration where the contact selectivity may be modified by the processing conditions of the active layer. It is important to note that in the regular configuration $\mathrm{EQE}$ and $\mathrm{C}-\mathrm{V}$ provide information on the same contact $(\mathrm{Ca} / \mathrm{Ag})$. Alternatively, in the inverted configuration EQE provide information on the anode $\left(\mathrm{MoO}_{3} / \mathrm{Ag}\right)$ and $\mathrm{C}-\mathrm{V}$ on the cathode $(\mathrm{ZnO} / \mathrm{ITO})$. The same set of processing conditions have been tested for the inverted configuration but for simplicity we do not discuss here the details, full information is shown as Supporting Information. Again, in the inverted configuration the thermal treatment promotes the transport of fullerene molecules towards the active layer/air interface where the contact selective to holes will be deposited $\left(\mathrm{MoO}_{3} / \mathrm{Ag}\right)$. This high coverage of fullerene molecules of the anode contact is detected by the EQE measurements where the relative contribution of fullerene will be enlarged as compared to the devices prepared with only a solvent annealing treatment. This large fullerene coverage is in good agreement with the expected high leakage current at negative bias as the fullerenes have migrated to the selective collector to the opposite electrode. Overall, in the two systems under study the thermal treatment promotes the migration of fullerene molecules to the active layer/air interface. Whilst in the regular configuration this will improve the contact selectivity as fullerene are close to the selective layer to electrons, in the inverted configuration the effect will be the opposite.

\section{Conclusions}

In the present work, the high impact of vertical segregation of donor and acceptor molecules on the contact selectivity of devices to be used for low intensity applications is explored. It is observed that a thermal treatment of the organic layer induces the fullerene migration towards the active layer/air interface. The amount of fullerene molecules covering the surface will determine the contact selectivity and leakage current of the device once the back contact is deposited. Control of this leakage current may not be essential for devices fabricated for high illumination conditions applications. However, devices to be used under low illumination conditions may be highly influenced by the presence of this parasitic dark current which flows in the opposite direction to photogenerated current. The present work provides some tools to better 
understand the difference in the limitations observed for devices to be used under low illumination conditions. By using a combination of optical and electrical techniques we are able to show that devices which contain high proportion of fullerene molecules at the cathode are highly selective and do not suffer from shunting. The extracted conclusions are not only applicable to organic photovoltaic devices but it can also be extrapolated to photodetectors where the leakage needs to be minimized (the dark current should be minimized in order to enhance the sensitivity/responsitivy of the detector).

\section{Acknowledgement}

This work was partially supported by FP7 European collaborative project SUNFLOWER (FP7-ICT-2011-7-contract num. 287594), and Generalitat Valenciana (project ISIC/2012/008 Institute of Nanotechnologies for Clean Energies). A.K. acknowledges Brno University of Technology for financial support (CZ.1.07/2.3.00/30.0039). We thank Prof. Sara Bals and Dr. Martin Pfannmöller from EMAT (University of Antwerp) for kindly providing dark field TEM images of films.

\section{Supporting information}

Supporting information includes data on contacts and device transparency, film morphology, information to calculate fullerene content by $\mathrm{C}-\mathrm{V}$ and an analogous study for inverted device configuration. This information is available free of charge via the Internet at http://pubs.acs.org/

\section{References}

1. Green, M. A.; Emery, K.; Hishikawa, Y.; Warta, W.; Dunlop, E. D., Solar Cell Efficiency Tables (version 39). Prog. Photovoltaics 2012, 20, 12-20.

2. Darling, S. B.; You, F., The Case for Organic Photovoltaics. RSC Adv. 2013, 3, 17633-17648.

3. Roland Steim, T. A., Pavel Schilinsky, Christoph Waldauf, Gilles Dennler, Markus Scharber, Christoph J. Brabec, Organic Photovoltaics for low Light Applications. Solar Energy Materials and Solar Cells 2011, 95, 3256-3261.

4. Reinhard, M.; Eckstein, R.; Slobodskyy, A.; Lemmer, U.; Colsmann, A., Solution-processed Polymer-silver Nanowire Top Electrodes for Inverted Semitransparent Solar Cells. Org. Electron. 2013, 14, 273-277. 
5. Kim, Y. H.; Sachse, C.; Zakhidov, A. A.; Meiss, J.; Zakhidov, A. A.; MüllerMeskamp, L.; Leo, K., Combined Alternative Electrodes for Semi-transparent and ITOFree Small Molecule Organic Solar Cells. Org. Electron. 2012, 13, 2422-2428.

6. Zhou, Y.; Cheun, H.; Choi, S.; Potscavage, W. J.; Fuentes-Hernandez, C.; Kippelen, B., Indium Tin Oxide-free and Metal-free Semitransparent Organic Solar Cells. Appl. Phys. Lett. 2010, 97, 153304.

7. Betancur, R.; Romero-Gomez, P.; Martinez-Otero, A.; Elias, X.; Maymo, M.; Martorell, J., Transparent Polymer Solar Cells Employing a Layered Light-trapping Architecture. Nat. Photonics 2013, 7, 995-1000.

8. Chen, C.-C.; Dou, L.; Gao, J.; Chang, W.-H.; Li, G.; Yang, Y., HighPerformance Semi-transparent Polymer Solar Cells Possessing Tandem Structures. Energy Environ. Sci. 2013, 6, 2714-2720.

9. Yang, X.; Loos, J., Toward High-Performance Polymer Solar Cells: The Importance of Morphology Control. Macromolecules 2007, 40, 1353-1362.

10. Yang, X.; Loos, J.; Veenstra, S. C.; Verhees, W. J. H.; Wienk, M. M.; Kroon, J. M.; Michels, M. A. J.; Janssen, R. A. J., Nanoscale Morphology of High-Performance Polymer Solar Cells. Nano Lett. 2005, 5, 579-583.

11. Li, G.; Zhu, R.; Yang, Y., Polymer Solar Cells. Nat. Photonics 2012, 6, 153-161.

12. Campoy-Quiles, M.; Ferenczi, T.; Agostinelli, T.; Etchegoin, P. G.; Kim, Y.; Anthopoulos, T. D.; Stavrinou, P. N.; Bradley, D. D. C.; Nelson, J., Morphology Evolution Via Self-organization and Lateral and Vertical Diffusion in Polymer:fullerene Solar Cell Blends. Nat. Mater. 2008, 7, 158-164.

13. Guerrero, A.; Dörling, B.; Ripolles-Sanchis, T.; Aghamohammadi, M.; Barrena, E.; Campoy-Quiles, M.; Garcia-Belmonte, G., Interplay Between Fullerene Surface Coverage and Contact Selectivity of Cathode Interfaces in Organic Solar Cells. ACS Nano 2013, 7, 4637-4646.

14. Li, G.; Shrotriya, V.; Huang, J.; Yao, Y.; Moriarty, T.; Emery, K.; Yang, Y., High-efficiency Solution Processable Polymer Photovoltaic Cells by Self-organization of Polymer Blends. Nat. Mater. 2005, 4, 864-868.

15. Chen, W.; Nikiforov, M. P.; Darling, S. B., Morphology Characterization in Organic and Hybrid Solar Cells. Energy Environ. Sci. 2012, 5, 8045-8074.

16. Liu, F.; Gu, Y.; Shen, X.; Ferdous, S.; Wang, H.-W.; Russell, T. P., Characterization of the Morphology of Solution-processed Bulk Heterojunction Organic Photovoltaics. Prog. Polym. Sci. 2013, 38, 1990-2052.

17. Guerrero, A.; Marchesi, L. F.; Boix, P. P.; Ruiz-Raga, S.; Ripolles-Sanchis, T.; Garcia-Belmonte, G.; Bisquert, J., How the Charge-Neutrality Level of Interface States Controls Energy Level Alignment in Cathode Contacts of Organic Bulk-Heterojunction 
Solar Cells. ACSNano 2012, 6, 3453-3460.

18. Guerrero, A.; Montcada, N. F.; Ajuria, J.; Etxebarria, I.; Pacios, R.; GarciaBelmonte, G.; Palomares, E., Charge Carrier Transport and Contact Selectivity Limit the Operation of PTB7-based Organic Solar Cells of Varying Active Layer Thickness. J. Mat. Chem. A 2013, 1, 12345-12354.

19. Etxebarria, I.; Guerrero, A.; Albero, J.; Garcia-Belmonte, G.; Palomares, E.; Pacios, R., Inverted vs Standard PTB7:PC70BM Organic Photovoltaic Devices. The Benefit of Highly Selective and Extracting Contacts in Device Performance. Org. Electron. 2014, 15, 2756-2762.

20. Guerrero, A.; Pfannmöller, M.; Kovalenko, A.; Ripolles, T. S.; Heidari, H.; Bals, S.; Kaufmann, L.-D.; Bisquert, J.; Garcia-Belmonte, G., Nanoscale Mapping by Electron Energy-loss Spectroscopy Reveals Evolution of Organic Solar Cell Contact Selectivity. Org. Electron. 2015, 16, 227-233.

21. Tremolet de Villers, B.; Tassone, C. J.; Tolbert, S. H.; Schwartz, B. J., Improving the Reproducibility of P3HT:PCBM Solar Cells by Controlling the PCBM/Cathode Interface. J. Phys. Chem. C 2009, 113, 18978-18982.

22. De Sio, A.; Madena, T.; Huber, R.; Parisi, J.; Neyshtadt, S.; Deschler, F.; Da Como, E.; Esposito, S.; von Hauff, E., Solvent Additives for Tuning the Photovoltaic Properties of Polymer-fullerene Solar Cells. Sol. Energy Mater. Sol. Cells 2011, 95, 3536-3542.

23. Lee, S. S.; Loo, Y.-L., Structural Complexities in the Active Layers of Organic Electronics. Annu. Rev. Chem. Biomol. Eng. 2010, 1, 59-78.

24. Tress, W.; Leo, K.; Riede, M., Photoconductivity as Loss Mechanism in Organic Solar Cells. Phys. Status Solidi RRL 2013, 7, 401-405. 
Table 1: Parameters of the polymer:fullerene devices.

\begin{tabular}{|c|c|c|c|c|c|c|c|c|c|c|c|c|c|}
\hline & \multicolumn{5}{|c|}{ Illumination from ITO/PEDOT:PSS } & \multicolumn{5}{|c|}{ Illumination from $\mathrm{Ag} / \mathrm{Ca}$} & \multicolumn{2}{|c|}{ Capacitance Voltage } & $\mathrm{J}-\mathrm{V}$ dark conditions \\
\hline & $\begin{array}{c}\mathrm{J}_{\mathrm{SC}} \\
{\left[\mathrm{mAcm}^{-2}\right]}\end{array}$ & $\begin{array}{c}\mathrm{V}_{\mathrm{OC}} \\
{[\mathrm{mV}]}\end{array}$ & $\begin{array}{l}\mathrm{FF} \\
{[\%]}\end{array}$ & $\begin{array}{c}\eta \\
{[\%]}\end{array}$ & $\begin{array}{c}\mathrm{R}_{\mathrm{sh}}, \\
{\left[\mathrm{Ohmcm}^{-2}\right]}\end{array}$ & $\begin{array}{c}\mathrm{J}_{\mathrm{SC}} \\
{\left[\mathrm{mAcm}^{-2}\right]}\end{array}$ & $\begin{array}{c}\mathrm{V}_{\mathrm{OC}} \\
{[\mathrm{mV}]}\end{array}$ & $\begin{array}{l}\text { FF } \\
{[\%]}\end{array}$ & $\begin{array}{c}\eta \\
{[\%]}\end{array}$ & $\begin{array}{c}\mathrm{R}_{\mathrm{sh}}, \\
{\left[\mathrm{Ohmcm}^{-2}\right]}\end{array}$ & $\begin{array}{c}\mathrm{V}_{\mathrm{FB}} \\
\mathrm{V}\end{array}$ & $\begin{array}{c}\text { Fullerene cathode } \\
\text { coverage [\%] }\end{array}$ & $\begin{array}{c}\text { Leakage current at -1V } \\
{\left[\mathrm{mAcm}^{-2}\right]}\end{array}$ \\
\hline Solvent & 7.49 & 614 & 59 & 2.71 & 1269 & 2.21 & 570 & 62 & 0.78 & 4404 & 0.43 & 68 & 0.57 \\
\hline Solvent +Thermal & 7.01 & 617 & 60 & 2.59 & 2036 & 1.80 & 574 & 62 & 0.64 & 6482 & 0.35 & 97 & 0.18 \\
\hline
\end{tabular}




\section{Table of Contents(TOC)}

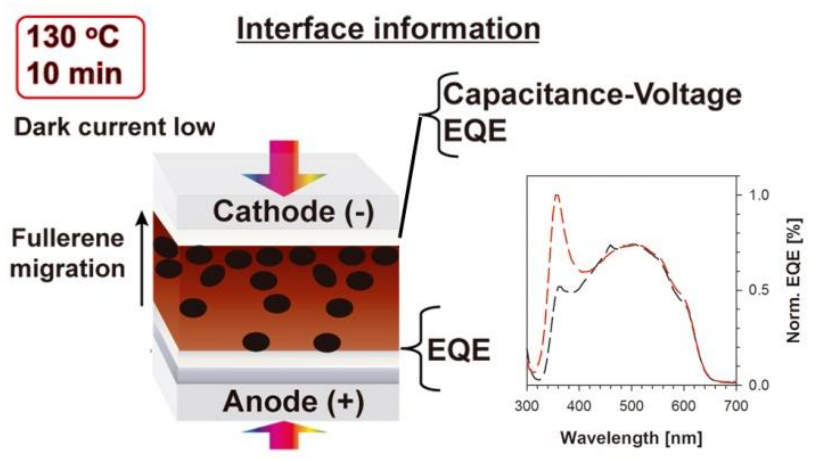

